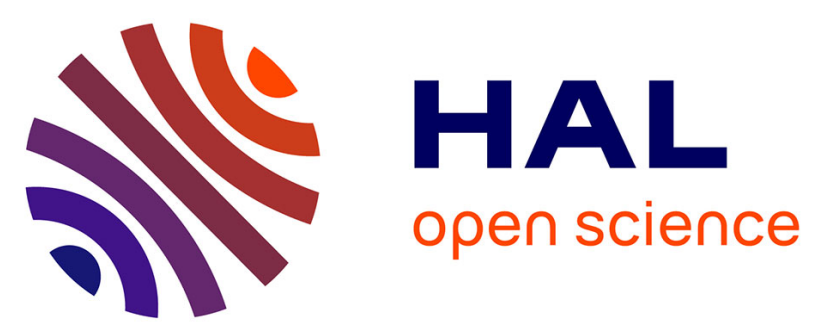

\title{
Halterman Corroles and Their Use as a Probe of the Conformational Dynamics of the Inherently Chiral Copper Corrole Chromophore
}

Kolle E Thomas, Laura J Mccormick, Daniel Carrie, Hugo Vazquez-Lima, Gerard Simonneaux, Abhik Ghosh

\section{To cite this version:}

Kolle E Thomas, Laura J Mccormick, Daniel Carrie, Hugo Vazquez-Lima, Gerard Simonneaux, et al.. Halterman Corroles and Their Use as a Probe of the Conformational Dynamics of the Inherently Chiral Copper Corrole Chromophore. Inorganic Chemistry, 2018, 57 (8), pp.4270-4276. 10.1021/acs.inorgchem.7b02767 . hal-01771518

HAL Id: hal-01771518

https://hal-univ-rennes1.archives-ouvertes.fr/hal-01771518

Submitted on 23 Aug 2018

HAL is a multi-disciplinary open access archive for the deposit and dissemination of scientific research documents, whether they are published or not. The documents may come from teaching and research institutions in France or abroad, or from public or private research centers.
L'archive ouverte pluridisciplinaire HAL, est destinée au dépôt et à la diffusion de documents scientifiques de niveau recherche, publiés ou non, émanant des établissements d'enseignement et de recherche français ou étrangers, des laboratoires publics ou privés. 


\title{
Halterman Corroles and Their Use as a Probe of the Conformational Dynamics of the Inherently Chiral Copper Corrole Chromophore
}

\author{
Kolle E. Thomas, ${ }^{\mathrm{a}}$ Laura J. McCormick, ${ }^{\mathrm{b}}$ Daniel Carrié, ${ }^{\mathrm{c}}$ Hugo Vazquez-Lima, ${ }^{\mathrm{a}}$ \\ Gérard Simonneaux, ${ }^{*, \mathrm{c}}$ and Abhik Ghosh${ }^{*, \mathrm{a}}$ \\ a Department of Chemistry, UiT - The Arctic University of Norway, N-9037 Tromsø, Norway; \\ b Advanced Light Source, Lawrence Berkeley National Laboratory, \\ Berkeley, CA 94720-8229, USA \\ cInstitut des Sciences Chimiques de Rennes UMR 6226 Université de Rennes 1 Campus de \\ Beaulieu 35042 Rennes, France
}

Email: gerard.simonneaux@univ-rennes1.fr(GS), abhik.ghosh@uit.no (AG)

\begin{abstract}
Halterman corroles have been synthesized for the first time from pyrrole and Halterman’s aldehyde via Gryko’s “water-methanol method”. These were derivatized to the corresponding copper complexes and subsequently also to the $\beta$-octabromo complexes. Electronic circular dichroism spectra were recorded for the enantiopure copper complexes, affording the first such measurements for the inherently chiral $\mathrm{Cu}$ corrole chromophore. Interestingly, for a given configuration of the Halterman substituents, X-ray crystallographic studies revealed both $P$ and $M$ conformations of the $\mathrm{Cu}$-corrole core, proving that the substituents, even in conjunction with $\beta$-octabromination, are unable to lock the Cu-corrole core into a given chirality. Indeed, the overall body of evidence strongly indicated a dynamic equilibrium between the $P$ and $M$ conformations. Such an interconversion, which presumably proceeds via saddling inversion, provides a rationale for our failure so far to resolve sterically hindered $\mathrm{Cu}$ corroles into their constituent enantiomers by means of chiral HPLC.
\end{abstract}

Note: The crystal structures described in this paper have been deposited at the Cambridge Crystallographic Data Centre and been assigned the following deposition numbers: CCDC 1576180-1576182. 
Introduction. The discovery of a new inherently chiral chromophore is a relatively uncommon occurrence. The concept, first introduced by Moscowitz and others over a half-century ago, 1,2 refers to molecular systems whose chirality cannot be ascribed to classic stereogenic elements, in particular stereogenic centers. ${ }^{3}$ Of particular interest from the point of view of chiroptical properties are inherently chiral chromophores with curved $\pi$-systems such as helicenes ${ }^{4}$ and certain fullerenes (e.g. $D_{2}-C_{76}, D_{3}-C_{78}, D_{2}-C_{80}$, and $\left.D_{2}-C_{84}\right) .{ }^{5}$ In the course of our own research on the coordination chemistry of corroles, ${ }^{6}$ we have discovered two different classes of inherently chiral chromophores. ${ }^{7}$ The first of these to be discovered, copper corroles, owe their chirality to an electronically driven saddling of the macrocycle, which allows an otherwise symmetry-forbidden $\mathrm{Cu}\left(\mathrm{d}_{\mathrm{x} 2-\mathrm{y} 2}\right)$-corrole $(\pi)$ orbital interaction. ${ }^{8,9,10,11,12}$ Steric crowding due to peripheral substituents can accentuate this saddling, but steric effects alone, in the absence of the electronic imperative, do not bring about saddling of the macrocycle. ${ }^{13}$ To our disappointent, so far we have not been able to resolve Cu corroles; chiral HPLC experiments have failed to resolve even highly saddled copper $\beta$-octabromo- ${ }^{14,15}$ and $\beta$-octakis(trifluoromethyl)- ${ }^{16,17}$ mesotriarylcorroles. ${ }^{18}$ In contrast, a second class of inherently chiral metallocorroles, $\mathrm{Mo}^{19}$ and $\mathrm{W}^{20}$ biscorroles, have been successfully resolved and the enantiomers of a $\mathrm{W}$ biscorrole have been chracterized via electronic circular dichroism spectroscopy. ${ }^{18}$

Herein, we have revisited the challenge of synthesizing copper corroles in scalemic (i.e., enantiomerically enriched) form by appending chiral substituents on the corrole periphery - a strategy that proved successful. Toward that end, we synthesized the corrole analogue of a Halterman porphyrin via the oxidative condensation of enantiopure 1,2,3,4,5,6,7,8-octahydro1:4,5:8-dimethanoanthracene-9-carboxaldehyde (hereafter referred to as $\mathfrak{H}_{6}$-CHO, where $\mathfrak{H}_{6}$ refers to the Halterman substituent of either chirality) and pyrrole. ${ }^{21,22}$ A modified version of Gryko’s water-methanol method, ${ }^{23}$ employing higher dilutions (to solubilize the relatively nonpolar aldehyde) and longer reaction times (16-18 h), led to good yields ( $40 \%)$ of the Halterman corroles (Figure 1). Copper was then inserted and the $\mathrm{Cu}$ complexes $\beta$-octabrominated with elemental bromine via standard protocols. ${ }^{8}$ Single-crystal X-structures were successfully obtained for three different $\mathrm{Cu}\left[\mathrm{H}_{3} \mathrm{Cor}\right]$ (Cor = corrole) derivatives. As discussed below, the structures clearly showed that the Halterman substituents in conjunction with $\beta$-octabromosubstitution are unable to lock the Cu-corrole conformation into a given chirality, which may be 
described by a P/M nomenclature as illustrated in Figure 2. The chemical implications of these findings are also discussed below.

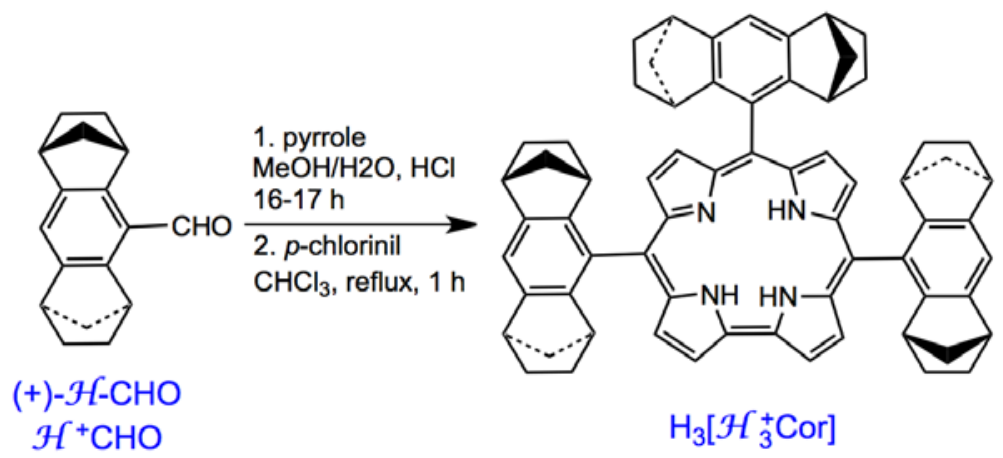

Figure 1. Synthesis of a Halterman corrole, where $\mathfrak{H C}^{+}$denotes the $(1 S, 4 R, 5 R, 8 S)-1,2,3,4,5,6,7,8-$ octahydro-1:4,5:8-dimethanoanthracen-9-yl substituent, which occurs in the $(+)$-isomer of the Halterman aldehyde; $\mathbb{H}_{6}$ denotes the same substituent of either chirality.
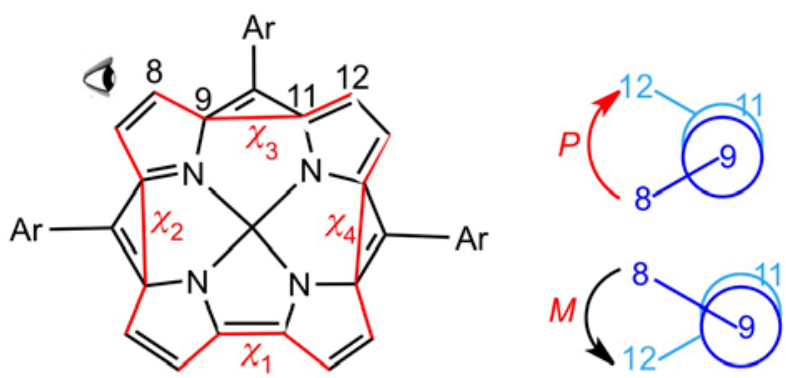

Figure 2. Definition of saddling torsion angles $\left(\chi_{1}-\chi_{4}\right)$. The inherent chirality of Cu corroles is defined here in terms of the sign of the $\mathrm{C}_{8}-\mathrm{C}_{9}-\mathrm{C}_{11}-\mathrm{C}_{12}\left(\chi_{3}\right)$ torsion angle.

Results and discussion. Table 1 presents crystal and refinement data for the three singlecrystal structures reported herein and Tables 2-4 present selected distances, angles, and torsion angles. In general, these structural parameters are similar to those of related Cu corrole structures reported in the literature. Some of the more notable aspects of the structures are as follows.

The X-ray structure of enantiopure $\mathrm{Cu}\left[\mathrm{He}^{+}{ }_{3} \mathrm{Cor}\right]$ (Figure 3 and Table 2) shows that all corrole units are identical and may be described as relatively mildly saddled, with only one moderately large saddling dihedral at $\sim 38^{\circ}$. The $\mathfrak{F}^{+}$substituents have led to a uniform $P$ configuration of the $\mathrm{Cu}$-corrole ring system. In contrast, the enantiopure $\beta$-octabrominated complex $\mathrm{Cu}\left[\mathrm{Br}_{8} \mathrm{H}_{6}^{-}{ }_{3} \mathrm{Cor}\right]$ was found to contain two unique $\mathrm{Cu}\left[\mathrm{Br}_{8} \mathrm{H}_{6}^{-}{ }_{3} \mathrm{Cor}\right]$ units, one with $M$ and the other with $P$ configuration, both of which exhibit a strongly saddled $\mathrm{Cu}$-corrole core with saddling dihedrals in the range $47-68^{\circ}$. There is some positional disorder involving the $10-9^{-}$ 
group of the $\mathrm{P}-\mathrm{Cu}\left[\mathrm{Br}_{8} \mathrm{H}_{6}^{-}{ }_{3} \mathrm{Cor}\right]$ unit; however, the enantiopurity of the molecule is not in question. 
Table 1. Crystal and refinement data for $\mathrm{Cu}$ Halterman corroles.

\begin{tabular}{|c|c|c|c|}
\hline Sample & $\mathrm{Cu}\left[\mathrm{He}_{3}^{+} \mathrm{Cor}\right]$ & $\mathrm{Cu}\left[\mathrm{Br}_{8} \mathrm{H}_{6}^{-}{ }_{3} \mathrm{Cor}\right]$ & $\begin{array}{c}\mathrm{Cu}\left[\mathrm{Br}_{8}-5,15-\mathrm{IJ}^{ \pm}{ }^{ \pm}-10-\right. \\
\left.\mathrm{Me}_{0}^{+} \mathrm{Cor}\right]\end{array}$ \\
\hline Chemical Formula & $\mathrm{C}_{69} \mathrm{H}_{63} \mathrm{Cl}_{4} \mathrm{CuN}_{4}$ & $\mathrm{C}_{73.75} \mathrm{H}_{66.56} \mathrm{Br}_{8} \mathrm{Cl}_{0.41} \mathrm{CuN}_{4}$ & $\mathrm{C}_{77.74} \mathrm{H}_{75.31} \mathrm{Br}_{8} \mathrm{Cl}_{1.71} \mathrm{CuN}_{4}$ \\
\hline Formula mass & 1153.57 & 1726.20 & 1828.90 \\
\hline Crystal system & Orthorhombic & Monoclinic & Monoclinic \\
\hline Space group & $P 2{ }_{1} 2{ }_{1}{ }_{1}$ & C2 & $C 2 / c$ \\
\hline$\lambda(\AA)$ & 0.7749 & 0.7749 & 0.7749 \\
\hline$a(\AA)$ & 11.8437(6) & $11.5580(6)$ & $11.4727(6)$ \\
\hline$b(\AA)$ & 17.9042(9) & 23.9229(12) & $23.9890(12)$ \\
\hline$c(\AA)$ & 26.3407(13) & 25.9436(13) & $25.9406(13)$ \\
\hline$\alpha\left(^{\circ}\right)$ & 90 & 90 & 90 \\
\hline$\beta\left({ }^{\circ}\right)$ & 90 & $91.359(2)$ & $91.002(3)$ \\
\hline$\gamma\left({ }^{\circ}\right)$ & 90 & 90 & 90 \\
\hline Z & 4 & 4 & 4 \\
\hline$V\left(\AA^{3}\right)$ & $5585.6(5)$ & 7171.4(6) & 7138.2(6) \\
\hline Temperature (K) & $100(2)$ & $100(2)$ & $100(2)$ \\
\hline$\rho\left(\mathrm{g} / \mathrm{cm}^{3}\right)$ & 1.372 & 1.599 & 1.702 \\
\hline Measured reflections & 386855 & 428802 & 40786 \\
\hline Unique reflections & 23535 & 28900 & 8921 \\
\hline Parameters & 703 & 843 & 391 \\
\hline Restraints & 0 & 122 & 84 \\
\hline$R_{i n t}$ & 0.0549 & 0.0618 & 0.0713 \\
\hline Abs. struct. parameter & $0.0300(14)$ & $0.028(3)$ & - \\
\hline$\theta$ range $\left(^{\circ}\right)$ & 1.499 to 38.123 & 0.856 to 37.450 & 1.712 to 31.276 \\
\hline$R 1, w R 2$ all data & $0.0475,0.1322$ & $0.0397,0.0929$ & $0.0713,0.1341$ \\
\hline$S(G o o F)$ all data & 1.085 & 1.052 & 1.109 \\
\hline $\begin{array}{c}\text { Max/min res. Dens. } \\
\left(\mathrm{e} / \AA^{3}\right)\end{array}$ & $1.242 /-1.653$ & $1.114 /-1.463$ & $1.459 /-1.119$ \\
\hline
\end{tabular}

Table 2. Selected distances $(\AA)$, angles $\left(^{\circ}\right)$, and torsion angles $\left(^{\circ}\right)$ for $\mathrm{Cu}\left[\mathrm{Y}_{0}^{+}{ }_{3} \mathrm{Cor}\right]$.

\begin{tabular}{ll}
\hline Distances & \\
$\mathrm{N}(1)-\mathrm{Cu}(1)$ & $1.8681(19)$ \\
$\mathrm{N}(2)-\mathrm{Cu}(1)$ & $1.8808(18)$ \\
$\mathrm{N}(3)-\mathrm{Cu}(1)$ & $1.8798(18)$ \\
$\mathrm{N}(4)-\mathrm{Cu}(1)$ & $1.879(2)$
\end{tabular}

\section{Angles}

$\mathrm{N}(1)-\mathrm{Cu}(1)-\mathrm{N}(4)$

81.74(9)

$\mathrm{N}(1)-\mathrm{Cu}(1)-\mathrm{N}(3)$

169.48(9)

$\mathrm{N}(4)-\mathrm{Cu}(1)-\mathrm{N}(3)$

91.74(8)

$\mathrm{N}(1)-\mathrm{Cu}(1)-\mathrm{N}(2)$

90.68(8)

$\mathrm{N}(4)-\mathrm{Cu}(1)-\mathrm{N}(2)$

$\mathrm{N}(3)-\mathrm{Cu}(1)-\mathrm{N}(2)$
167.66(9)

97.08(8)

\begin{tabular}{ll} 
Torsion angles & \\
$\mathrm{C}(3)-\mathrm{C}(4)-\mathrm{C}(6)-\mathrm{C}(7)$ & $-16.9(8)$ \\
$\mathrm{C}(8)-\mathrm{C}(9)-\mathrm{C}(11)-\mathrm{C}(12)$ & $22.4(7)$ \\
$\mathrm{C}(13)-\mathrm{C}(14)-\mathrm{C}(16)-\mathrm{C}(17)$ & $-38.3(8)$ \\
$\mathrm{C}(18)-\mathrm{C}(19)-\mathrm{C}(1)-\mathrm{C}(2)$ & $16.8(6)$ \\
\hline
\end{tabular}


Table 3. Selected distances $(\AA)$, angles $\left(^{\circ}\right)$, and torsion angles $\left(^{\circ}\right)$ for $\mathrm{Cu}\left[\mathrm{Br}_{8} \mathrm{HC}_{3}^{-} \mathrm{Cor}\right]$.

\begin{tabular}{ll|lr}
\hline Distances & \multicolumn{3}{|l}{ Angles } \\
$\mathrm{Cu}(1)-\mathrm{N}(1)$ & $1.910(3)$ & $\mathrm{N}(1)-\mathrm{Cu}(1)-\mathrm{N}(1)^{\mathrm{I}}$ & $82.5(2)$ \\
$\mathrm{Cu}(1)-\mathrm{N}(2)$ & $1.914(3)$ & $\mathrm{N}(1)-\mathrm{Cu}(1)-\mathrm{N}(2)^{\mathrm{I}}$ & $168.88(17)$ \\
$\mathrm{Cu}(2)-\mathrm{N}(101)$ & $1.915(3)$ & $\mathrm{N}(1)-\mathrm{Cu}(1)-\mathrm{N}(2)$ & $90.71(15)$ \\
$\mathrm{Cu}(2)-\mathrm{N}(102)$ & $\mathrm{N}(2)^{\mathrm{I}}-\mathrm{Cu}(1)-\mathrm{N}(2)$ & $97.3(2)$ \\
& $\mathrm{N}(101)^{\mathrm{II}}-\mathrm{Cu}(2)-\mathrm{N}(101)$ & $82.92(19)$ \\
& $\mathrm{N}(101)-\mathrm{Cu}(2)-\mathrm{N}(102)$ & $90.56(13)$ \\
& $\mathrm{N}(101)^{\mathrm{II}}-\mathrm{Cu}(2)-\mathrm{N}(102)^{\mathrm{II}}$ & $90.57(13)$ \\
& $\mathrm{N}(101)-\mathrm{Cu}(2)-\mathrm{N}(102)^{\mathrm{II}}$ & $168.49(14)$ \\
& $\mathrm{N}(102)-\mathrm{Cu}(2)-\mathrm{N}(102)^{\mathrm{II}}$ & $97.35(19)$ \\
\hline
\end{tabular}

\begin{tabular}{lc}
\hline Torsion angles & \\
C(3)-C(4)-C(6)-C(7) & $67.4(15)$ \\
C(8)-C(9)-C(9) ${ }^{\mathrm{I}}-\mathrm{C}(8)^{\mathrm{I}}$ & $-59(2)$ \\
$\mathrm{C}(2)-\mathrm{C}(1)-\mathrm{C}(1)^{\mathrm{I}}-\mathrm{C}(2)^{\mathrm{I}}$ & $-51.0(14)$ \\
$\mathrm{C}(103)-\mathrm{C}(104)-\mathrm{C}(106)-\mathrm{C}(107)$ & $-67.6(11)$ \\
$\mathrm{C}(108)-\mathrm{C}(109)-\mathrm{C}(109)^{\mathrm{II}}-\mathrm{C}(108)^{\mathrm{II}}$ & $50.2(15)$ \\
$\mathrm{C}(102)-\mathrm{C}(101)-\mathrm{C}(101)^{\mathrm{II}}-\mathrm{C}(102)^{\mathrm{II}}$ & $47.4(12)$ \\
\hline
\end{tabular}

Symmetry transformations used to generate equivalent atoms:

I: $-\mathrm{X}+1, \mathrm{y},-\mathrm{z} \quad$ II: $-\mathrm{x}+1, \mathrm{y},-\mathrm{z}+1$

Table 4. Selected distances $(\AA)$, angles $\left(^{\circ}\right)$, and torsion angles $\left(^{\circ}\right)$ for $\mathrm{Cu}\left[\mathrm{Br}_{8} 5,15-\mathrm{M}_{\mathrm{C}^{ \pm}}{ }_{2}-10-\mathrm{IC}^{\mp} \mathrm{Cor}\right]$.

\begin{tabular}{l|lc}
\hline Distances & Angles & \\
$\mathrm{N}(1)-\mathrm{Cu}(1) 1.906(4)$ & $\mathrm{N}(1)-\mathrm{Cu}(1)-\mathrm{N}(1)^{\mathrm{I}}$ & $82.5(2)$ \\
$\mathrm{N}(2)-\mathrm{Cu}(1) 1.921(4)$ & $\mathrm{N}(1)-\mathrm{Cu}(1)-\mathrm{N}(2)$ & $91.02(17)$ \\
& $\mathrm{N}(1)-\mathrm{Cu}(1)-\mathrm{N}(2)^{\mathrm{I}}$ & $168.95(19)$ \\
& $\mathrm{N}(2)-\mathrm{Cu}(1)-\mathrm{N}(2)^{\mathrm{I}}$ & $96.7(2)$ \\
\hline
\end{tabular}

Torsion angles

$\mathrm{C}(3)-\mathrm{C}(4)-\mathrm{C}(6)-\mathrm{C}(7)$

$-63.0(18)$

$\mathrm{C}(8)-\mathrm{C}(9)-\mathrm{C}(9) \# 1-\mathrm{C}(8) \# 1$

$57(2)$

$\mathrm{C}(2)-\mathrm{C}(1)-\mathrm{C}(1) \# 1-\mathrm{C}(2) \# 1$

$47.9(16)$

Symmetry transformations used to generate equivalent atoms:

I: $-\mathrm{x}+1, \mathrm{y},-\mathrm{z}+1 / 2$ 

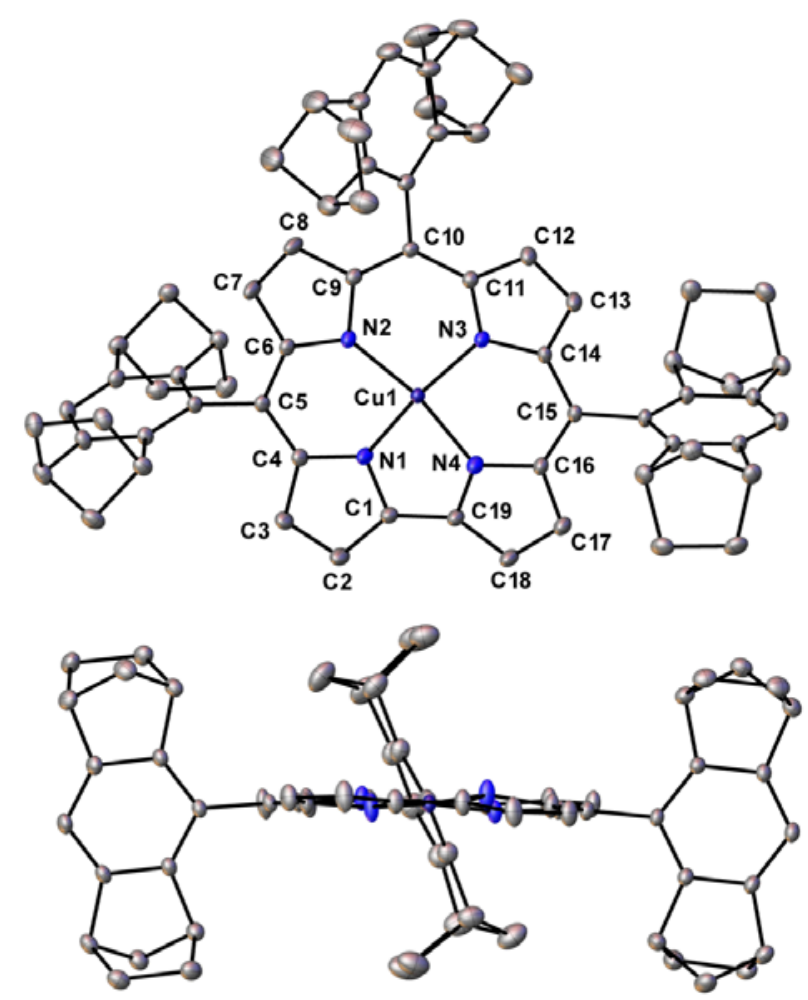

Figure 3. Top and side views of the X-ray structure of $\mathrm{Cu}\left[\mathrm{He}_{3}^{+} \mathrm{Cor}\right]$. Thermal ellipsoids for this and all subsequent figures are shown at 50\% probability.
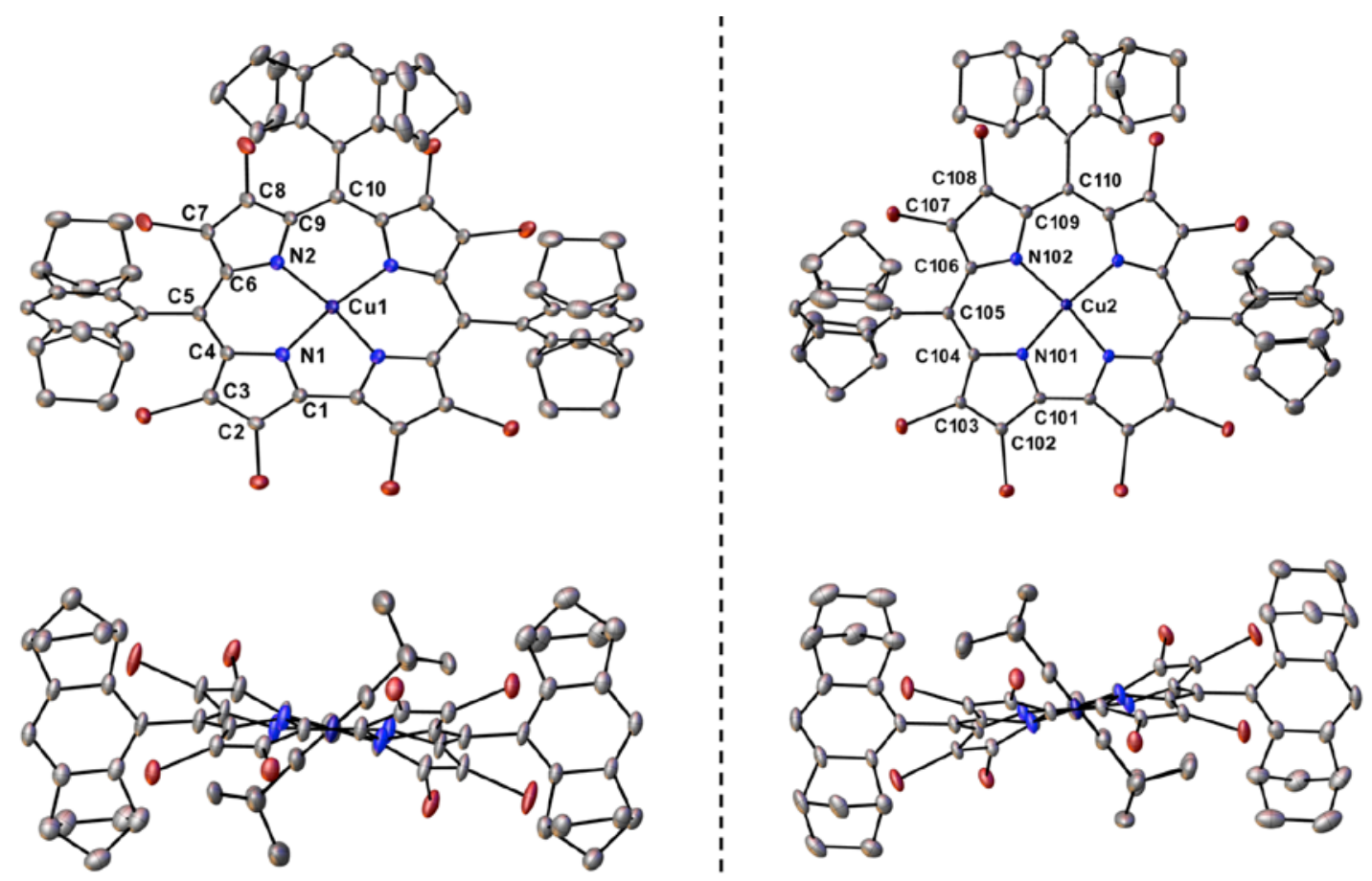

Figure 4. X-ray structure of $\mathrm{Cu}\left[\mathrm{Br}_{8} \mathrm{H}_{3}^{-} \mathrm{Cor}\right]$ containing an equimolar distribution of the $P$ (left) and $M$ (right) conformations. The thermal ellipsoids have been drawn at $50 \%$ probability. 

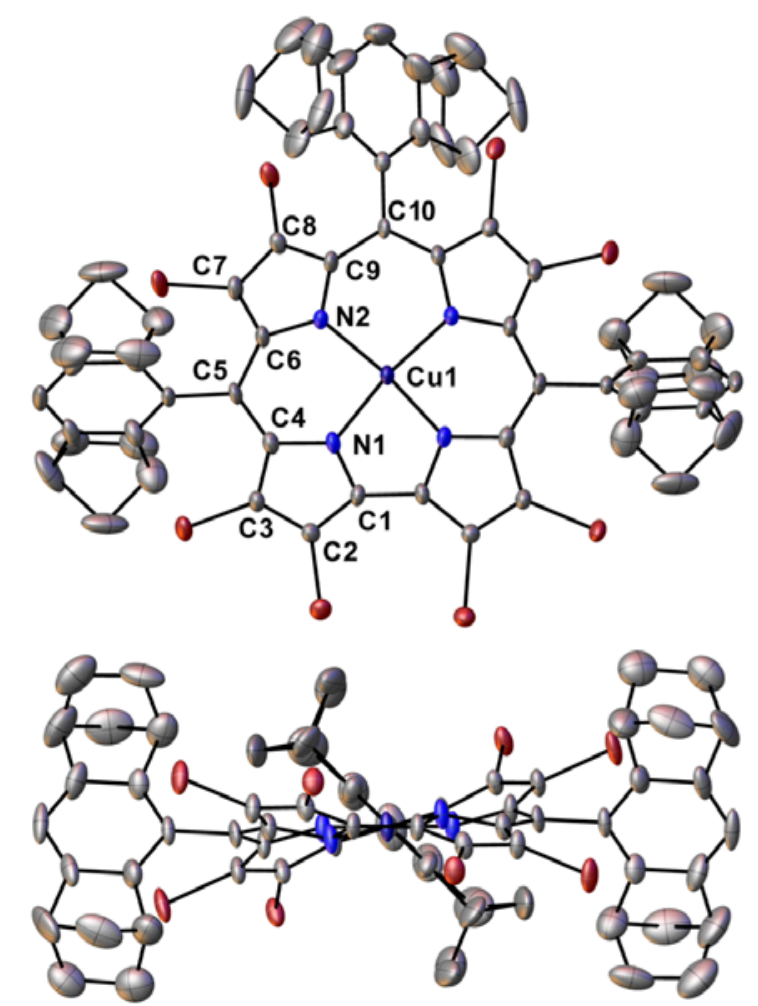

Figure 5. Top and side views of the molecular structure of racemic $\mathrm{Cu}\left[\mathrm{Br}_{8}-5,15-\mathscr{H}_{6}^{ \pm}{ }_{2}-10-\mathrm{IO}_{6}^{\mp} \mathrm{Cor}\right]$. The molecule shown is the $\mathrm{P}-\mathrm{Cu}\left[\mathrm{Br}_{8} 5,15-\mathrm{H}_{2}^{-}-10-\mathrm{Pl}^{+} \mathrm{Cor}\right]$ enantiomer and, for clarity, only the major orientation of the ${ }^{\circ}$ groups are shown. The thermal ellipsoids have been drawn at $50 \%$ probability.

X-ray analysis revealed that the use of $( \pm)-H_{6}-\mathrm{CHO}$ in the corrole synthesis and subsequent bromination leads almost exclusively to $\mathrm{Cu}\left[\mathrm{Br}_{8}-5,15-\mathrm{Ye}_{0}^{ \pm}{ }_{2}-10-\mathrm{YC}_{0}^{\mp} \mathrm{Cor}\right]$ (i.e., a diastereomer of $\left.\mathrm{Cu}\left[\mathrm{Br}_{8} \mathrm{Yl}_{3}^{+} \mathrm{Cor}\right] / \mathrm{Cu}\left[\mathrm{Br}_{8} \mathrm{YC}_{3}^{-} \mathrm{Cor}\right]\right)$, in which the Halterman substituent at the 10position has a different chirality relative to the 5- and 15-substituents (Figure 5 and Table 3). Not

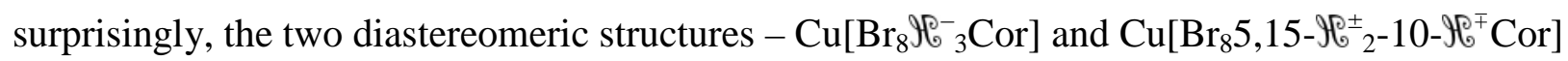
- were found to be very similar in terms of key structural parameters such as $\mathrm{Cu}-\mathrm{N}$ distances and saddling dihedrals. Also, as in the case of $\mathrm{Cu}\left[\mathrm{Br}_{8} \mathrm{He}_{3}^{-} \mathrm{Cor}\right]$, the crystal structure of racemic $\mathrm{Cu}\left[\mathrm{Br}_{8}-5,15-\mathrm{Se}_{2}^{ \pm}-10-\mathrm{IE}^{\mp} \mathrm{Cor}\right]$ revealed evidence of conformational multiplicity for both enantiomers. Thus, all three $H_{6}$ groups on a given molecule were found to exhibit a small amount ( 14\%) of disorder, indicating that although a majority of the $\mathrm{Cu}$-corrole units in the $\mathrm{Cu}\left[\mathrm{Br}_{8}\right.$ $\left.5,15-\mathscr{Y C}_{2}^{-}-10-\mathrm{IC}^{+} \mathrm{Cor}\right]$ enantiomer exhibits a $P$ conformation, a small proportion of the molecules ( $14 \%$ ) exhibits an M conformation. Obviously, analogous observations apply for the other enantiomer. 
The scalemic products $\mathrm{Cu}\left[\mathrm{He}_{3}^{+} \mathrm{Cor}\right] / \mathrm{Cu}\left[\mathrm{YC}_{3}^{-} \mathrm{Cor}\right]$ and $\mathrm{Cu}\left[\mathrm{Br}_{8} \mathrm{MP}_{3}^{+} \mathrm{Cor}\right] / \mathrm{Cu}\left[\mathrm{Br}_{8} \mathrm{HC}_{3}^{-} \mathrm{Cor}\right]$ were also characterized via electronic circular dichroism (ECD) spectroscopy (Figure 6). The key spectral features clearly correspond to the Soret and Q bands of the complexes, indicating that they arise largely from the Cu-corrole moiety and not from the substituents. Observable ECD spectra also strongly suggest that the $P$ and $M$ conformations are present in unequal amounts in solution, in contrast to the $1: 1 \mathrm{P} / \mathrm{M}$ ratio found in the X-ray structure of $\mathrm{Cu}\left[\mathrm{Br}_{8} \mathrm{H}^{-}{ }_{3} \mathrm{Cor}\right]$, implying a dynamic equilibrium between the $P$ and $M$ conformations in solution. Such a conclusion is also in accord with DFT calculations (Table 4), which indicate exceedingly small energy differences between the $P$ and $M$ conformations for all the molecules studied.

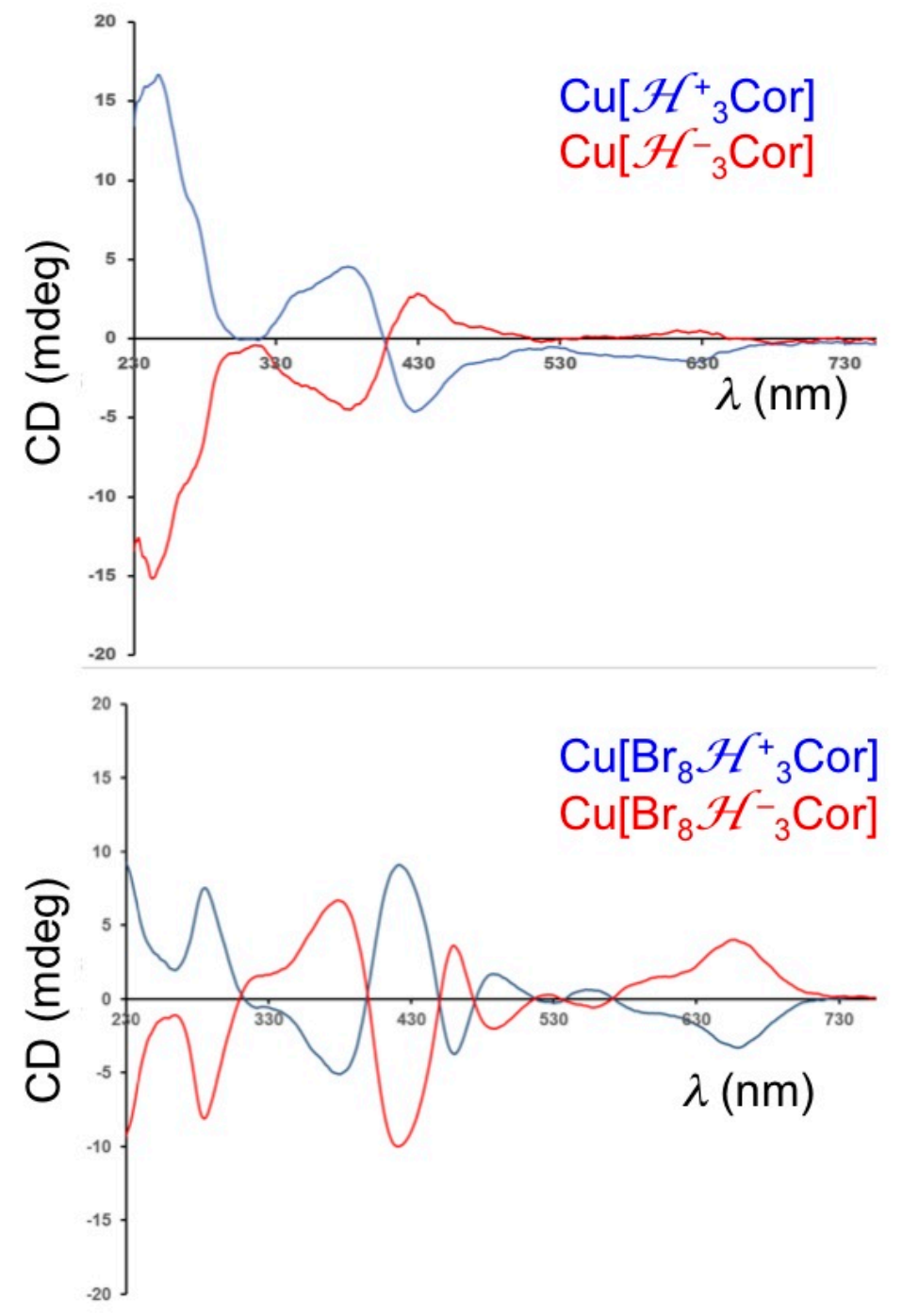

Figure 6. Circular dichroism spectra of $\mathrm{Cu}\left[\mathrm{He}_{3}^{+} \mathrm{Cor}\right] / \mathrm{Cu}\left[\mathrm{He}_{3}^{-} \mathrm{Cor}\right]$ and $\mathrm{Cu}\left[\mathrm{Br}_{8} \mathrm{He}_{3}^{+} \mathrm{Cor}\right] /$ $\mathrm{Cu}\left[\mathrm{Br}_{8} \mathrm{HO}_{3}^{-} \mathrm{Cor}\right]$. 
Table 4. OLYP/TZ2P relative energetics $(\mathrm{eV})$ and saddling dihedrals $\left(^{\circ}\right)$.

\begin{tabular}{|c|c|c|c|c|c|}
\hline & & & \multicolumn{3}{|c|}{ Saddling dihedral $^{\mathrm{a}}$} \\
\hline Molecule & Conformation & $E_{\text {rel }}$ & $\chi_{1}$ & $\chi_{2} / \chi_{4}$ & $\chi_{3}$ \\
\hline \multirow[t]{2}{*}{$\mathrm{Cu}\left[\mathrm{He}_{3}^{+} \mathrm{Cor}\right]$} & $\mathrm{P}$ & 0.094 & 25.5 & -42.1 & 33.4 \\
\hline & & & $16.8(6)$ & $-16.9(8) /-38.3(8)$ & $22.4(7)$ \\
\hline $\mathrm{Cu}\left[\mathrm{He}_{3}^{+} \mathrm{Cor}\right]$ & $M$ & 0.023 & -24.1 & 42.2 & -33.5 \\
\hline $\mathrm{Cu}\left[5,15-\mathrm{I}_{0}^{+} 2-10-\mathrm{J}_{0}^{-} \mathrm{Cor}\right]$ & $P$ & 0.120 & 26.5 & -43.4 & 36.0 \\
\hline $\mathrm{Cu}\left[5,15-\mathrm{J}^{+}{ }^{+}-10-\mathrm{I}^{-} \mathrm{Cor}\right]$ & $M$ & 0.000 & -23.0 & 41.4 & -33.9 \\
\hline \multirow[t]{2}{*}{$\mathrm{Cu}\left[\mathrm{Br}_{8} \mathrm{H}_{6}^{+}{ }_{3} \mathrm{Cor}\right]$} & $P$ & 0.081 & 50.1 & -69.4 & 64.8 \\
\hline & & & 47.4(12) & $-67.6(11)$ & $50.2(15)$ \\
\hline \multirow[t]{2}{*}{$\mathrm{Cu}\left[\mathrm{Br}_{8} \mathrm{MO}_{3}^{+} \mathrm{Cor}\right]$} & $M$ & 0.018 & -49.6 & 69.1 & -62.9 \\
\hline & & & $-51.0(14)$ & 67.4(15) & $-59(2)$ \\
\hline \multirow[t]{2}{*}{$\mathrm{Cu}\left[\mathrm{Br}_{8} 5,15-\mathrm{Ne}_{2}^{+}-10-\mathrm{Ne}_{0}^{-} \mathrm{Cor}\right]$} & $P$ & 0.101 & 50.0 & -68.6 & 63.8 \\
\hline & & & 47.9(16) & $-63.0(18)$ & $57(2)$ \\
\hline $\mathrm{Cu}\left[\mathrm{Br}_{8} 5,15-\mathrm{He}_{2}^{+}-10-\mathrm{He}_{6}^{-} \mathrm{Cor}\right]$ & $M$ & 0.000 & -48.8 & 68.3 & -63.7 \\
\hline
\end{tabular}

* The values in bold have been obtained from the crystallographic structures.

It is worth noting that the calculated energetics does not offer any insights into why racemic $\mathrm{Ye}_{6}-\mathrm{CHO}$ should selectively afford the $\mathrm{H}_{3}\left[5,15-\mathrm{SO}_{2}^{ \pm}{ }_{2}-10-\mathrm{H}_{6}^{\mp} \mathrm{Cor}\right]$ diastereomer as opposed to $\mathrm{H}_{3}\left[\mathrm{IC}_{3}^{+} \mathrm{Cor}\right] / \mathrm{H}_{3}\left[\mathrm{He}_{3}^{-} \mathrm{Cor}\right]$. A comparison of the relative energies of the corresponding $\mathrm{Cu}$ complexes (in their lowest-energy conformations) proved unenlightening, since they are essentially identical.

Conclusion. In summary, the first Halterman corrole ligand has been synthesized in reasonably good yield and derivatized to the corresponding $\mathrm{Cu}$ complexes as well as to the $\beta$ octabrominated Cu complexes. Access to the inherently chiral Cu-corrole chromophore in scalemic form has allowed us to record its electronic circular dichroism spectrum for the first time. Single-crystal X-ray structures were obtained for three different $\mathrm{Cu}$ complexes. Somewhat to our surprise, the structures proved that the Halterman substituents, even in conjunction with $\beta$ octabromo-substitution, are unable to lock the Cu-corrole conformation into a given chirality. While in one sense this finding may be considered disappointing, in another sense it sheds valuable light on the dynamics of copper corroles. Together with our inability to resolve copper $\beta$-octabromo- and $\beta$-octakis(trifluoromethyl)- meso-triarylcorroles, the present results underscore 
the facile interconversion of the $P$ and $M$ conformations of sterically hindered $\mathrm{Cu}$ corroles. Although we have not yet conclusively located a transition state for this process, we may speculate that saddling inversion provides for a plausible pathway. Finally, there can be no doubt that the present synthesis of Halterman corrole derivatives will open up the study of chiral metallocorroles as asymmetric catalysts, especially for group transfer ${ }^{24,25,26,27}$ reactions such as hydroxylation/epoxidation, ${ }^{28,29,30}$ aziridination, ${ }^{31,32,33}$ and cyclopropanation, $, 3,35,36,37,38$ an area where chiral metalloporphyrins already play a significant role. ${ }^{39,40,41}$

\section{Experimental Section}

Materials and Instruments. All reagents and solvents were used as purchased except pyrrole, which was purified by passing through a pad of basic aluminum oxide 60 (Activity I, 0.063$0.200 \mathrm{~mm}$ particle size, Merck Millipore). The Halterman aldehydes (1S,4R,5R,8S)1,2,3,4,5,6,7,8-octahydro-1:4,5:8-dimethanoanthracene-9-carboxaldehyde and its enantiomer as well as the corresponding racemate were synthesized as reported. ${ }^{21}$ Free-base Halterman corroles were synthesized according to a modified version of Gryko’s method employing sterically hindered dipyrromethane. ${ }^{23}$ Copper complexes were prepared as previously described. ${ }^{8}$ Silica gel 150 (35-70 $\mu \mathrm{m}$ particle size, Davisil) was generally used for column chromatography. Silica gel 60 preparative thin-layer chromatography plates $(20$ x $20 \mathrm{~cm}$; $0.5 \mathrm{~mm}$ thick, Merck) were used for final purification of all compounds. UV-vis spectra were recorded on an HP 8453 spectrophotometer at room temperature in $\mathrm{CH}_{2} \mathrm{Cl}_{2}$. Proton NMR spectra were recorded on a Mercury Plus Varian spectrometer at $400 \mathrm{MHz}$ in $\mathrm{CDCl}_{3}$ and referenced to residual $\mathrm{CHCl}_{3}$ at $\delta=$ 7.26 ppm. High-resolution electrospray ionization (ESI) mass spectra were recorded on an LTQ Orbitrap XL spectrometer.

\section{Common synthetic procedure for 5,10,15-tris $[(1 S, 4 R, 5 R, 8 S)-1,2,3,4,5,6,7,8-$} octahydro-1:4,5:8-dimethanoanthracen-9-yl]corrole, $\mathrm{H}_{3}\left[\mathscr{Y}^{+}{ }_{3} \mathrm{Cor}\right]$, its enantiomer, and its racemate. To the Halterman aldehyde (480 mg, $2 \mathrm{mmol}$ ) thoroughly dissolved in $\mathrm{MeOH}$ (600 $\mathrm{mL}$ ) was added pyrrole (279 $\mu \mathrm{L}, 4 \mathrm{mmol})$, followed by a solution made from $37 \% \mathrm{HCl}(16.5$ $\mathrm{mL})$ diluted in distilled water $(300 \mathrm{~mL})$. The resulting mixture was stirred overnight for about 16-17 h. The orange suspension obtained was extracted with $\mathrm{CHCl}_{3}$ and the organic phase was washed twice with distilled water. The olive-green organic phase was dried with anhydrous $\mathrm{Na}_{2} \mathrm{SO}_{4}$ and filtered. The filtrate was diluted with $\mathrm{CHCl}_{3}$ to a volume of $450 \mathrm{~mL}$ and refluxed for $1 \mathrm{~h}$ with $p$-chloranil (991 mg, $4 \mathrm{mmol}$ ). The suspension obtained was concentrated to a 
minimum volume and chromatographed on a silica gel column with $1: 1 n$-hexane/ $\mathrm{CH}_{2} \mathrm{Cl}_{2}$ as eluent, yielding the free-base corrole as the first brown band. Yield: $235 \mathrm{mg}$ (38.2\%). UV-Vis $\lambda_{\max }(\mathrm{nm}), \varepsilon \times 10^{-4}\left(\mathrm{M}^{-1} \mathrm{~cm}^{-1}\right)$ : 388 (8.83), 399 (8.12), 419 (6.51), 548 (0.80), 703 (0.40). ${ }^{1} \mathrm{H}$ NMR: $\delta$-0.54 to 0.75 (br); 0.92 - 1.19 (br); 1.26 - 1.45 (m, br); $1.74-2.20$ (m, br). HR-MS (ESI ${ }^{+}$, major isotopomer): $[\mathrm{M}+\mathrm{H}]^{+}=921.4901$ (expt), 921.4891 (calcd). Elemental analysis found (calcd): C, 86.68 (87.16); H, 6.80 (6.77), N, 6.08 (6.07).

\section{Synthesis of copper 5,10,15-tris[(1S,4R,5R,8S)-1,2,3,4,5,6,7,8-octahydro-1:4,5:8-} dimethanoanthracene-9-yl]corrole, its enantiomer, and its racemate, $\mathrm{Cu}\left[\mathscr{Y}_{63} \mathrm{Cor}\right.$. Copper acetate (4 equiv, $43 \mathrm{mg}$ ) was added to a solution of the free-base (50 mg, $0.054 \mathrm{mmol}$ ) in $5 \mathrm{~mL}$ pyridine. After stirring for $20 \mathrm{~min}$, the suspension was evaporated to a brown residue which was dissolved in a minimum volume of $\mathrm{CHCl}_{3}$ and eluted through a silica gel column with 7:3 nhexane/ $\mathrm{CH}_{2} \mathrm{Cl}_{2}$. The copper corrole was eluted as brown bands. Yield: $47 \mathrm{mg}(88.5 \%)$. UV-Vis $\lambda_{\text {max }}(\mathrm{nm}), \varepsilon \times 10^{-4}\left(\mathrm{M}^{-1} \mathrm{~cm}^{-1}\right): 411$ (7.84), 541 (0.90), 653 (0.20). ${ }^{1} \mathrm{H}$ NMR: $\delta 0.81-0.87$ (m, $3 \mathrm{H}$, $\mathrm{CH}_{2}$ ); 0.92 - 1.01 (m, 3 H, $\mathrm{CH}_{2}$ ); 1.15 - 1.21 (m, $6 \mathrm{H}, \mathrm{CH}_{2}$ ); 1.35 (d, $2 \mathrm{H}, \mathrm{CH}_{2}$ ); 1.39 (d, $2 \mathrm{H}$, $\left.\mathrm{CH}_{2}\right) ; 1.44$ (d, $\left.2 \mathrm{H}, \mathrm{CH}_{2}\right) ; 1.62-1.73\left(\mathrm{~m}, 9 \mathrm{H}, \mathrm{CH}_{2}\right) ; 1.77-1.88$ (m, $\left.9 \mathrm{H}, \mathrm{CH}_{2}\right) ; 2.98$ (br s, $2 \mathrm{H}$, CH); 3.09 (br s, 2 H, CH); 3.27 (br s, 2 H, CH); 3.37 (br d, 4 H, CH); 3.42 (br d, 2 H, CH); 7.02 (d, 2 H, $\beta$-H); 7.04 (s,1 H, p-H); 7.09 (s, 2 H, p-H); 7.22 (br s, 2H); 7.39 (br d, 2 H, $\beta$-H); 8.01 (br s, 2 H, $\beta$-H). HR-MS (ESI ${ }^{+}$, major isotopomer): $[\mathrm{M}]^{+}=982.4044$ (expt), 982.4030 (calcd). Elemental analysis found (calcd): C, 81.10 (81.80); H, 5.86 (6.04); N, 5.32 (5.70).

\section{Synthesis of copper 2,3,7,8,12,13,17,18-octabromo-5,10,15-tris(1,2,3,4,5,6,7,8-}

octahydro-1:4,5:8-dimethanoanthracen-9-yl]corrole, $\mathrm{Cu}\left[\mathrm{Br}_{8}{ }_{\mathrm{H}_{3}} \mathrm{Cor}\right]$. The $\mathrm{Cu}\left[\mathscr{H}_{3} \mathrm{Cor}\right]$ starting material (30 mg, $0.03 \mathrm{mmol}$ ) was dissolved in $\mathrm{CHCl}_{3}(15 \mathrm{~mL})$ and to the solution was added $\mathrm{Br}_{2}$ (2.44 mmol, $125 \mu \mathrm{L}, 80$ equiv), dissolved in $\mathrm{CHCl}_{3}(10 \mathrm{~mL})$, in a dropwise manner over $20 \mathrm{~min}$. The resulting suspension was stirred for $1 \mathrm{~h}$, following which pyridine (203 $\mu \mathrm{L}, 2.52 \mathrm{mmol}, 84$ equiv) dissolved in $\mathrm{CHCl}_{3}(10 \mathrm{~mL})$ was added dropwise over $20 \mathrm{~min}$. The resulting mixture was again stirred for $1 \mathrm{~h}$ and then shaken with an equal volume of $20 \% \mathrm{w} / \mathrm{v}$ aqueous $\mathrm{Na}_{2} \mathrm{~S}_{2} \mathrm{O}_{7}$. The organic phase was then dried over anhydrous $\mathrm{Na}_{2} \mathrm{SO}_{4}$, filtered, and evaporated to a minimum. Column chromatography on silica gel with $13: 7 n$-hexane $/ \mathrm{CH}_{2} \mathrm{Cl}_{2}$ resulted in brown bands, which were combined and evaporated to yield the crude product, which was further purified by crystallization from 1:1 $\mathrm{CH}_{3} \mathrm{OH} / \mathrm{CHCl}_{3}$. Yield: $30 \mathrm{mg}(62 \%)$. UV-Vis $\lambda_{\max }(\mathrm{nm}), \varepsilon \times 10^{-4}\left(\mathrm{M}^{-1} \mathrm{~cm}^{-}\right.$ 1): 411 (5.54), 457 (7.52), 547 (1.47), 651 (0.72). ${ }^{1} \mathrm{H}$ NMR: $\delta 1.07$ - 1.18 (m, 6H, $\left.\mathrm{CH}_{2}\right) ; 1.21$ 1.36 (m, $\left.8 \mathrm{H}, \mathrm{CH}_{2}\right) ; 1.39$ (d, $\left.2 \mathrm{H}, \mathrm{CH}_{2}\right) ; 1.42$ - 1.48 (m, $\left.4 \mathrm{H}, \mathrm{CH}_{2}\right) ; 1.57$ - 1.65 (m, $3 \mathrm{H}, \mathrm{CH}_{2}$ ); 
1.74 - 1.94 (m, 11 H, CH ); 2.03 (d, 2 H, $\mathrm{CH}_{2}$ ); 2.65 (bd, 2 H, CH); 2.83 (bd, 2 H, CH); 3.20 (br d, 2 H, CH); 3.27 (br d, 2 H, CH); 3.33 (br d, 2 H, CH); 3.36 (br d, 2 H, CH); 7.15 (s,1 H, p-H); 7.21 (s, 2 H, p-H). HR-MS (ESI ${ }^{+}$, major isotopomer): [M] ${ }^{+}=1613.6810$ (expt), 1613.6805 (calcd). Elemental analysis found (calcd) : C 49.41 (49.83), H, 2.98 (3.18), N 3.66 (3.47).

X-ray structure determination. X-ray data for all three crystalline materials were collected on beamline 11.3.1 at the Advanced Light Source, employing a Bruker D8 diffractometer equipped with a PHOTON100 CMOS detector operating in shutterless mode. The crystal was coated in protective oil prior to being mounted on a MiTeGen ${ }^{\circledR}$ kapton micromount and placed under a nitrogen stream at 100(2) K provided by an Oxford Cryostream 800 Plus low temperature apparatus. Diffraction data were collected using synchrotron radiation monochromated with $\mathrm{Si}(111)$ to a wavelength of $0.7749(1) \AA$. An approximate full-sphere of data was collected using a combination of phi and omega scans; multiple spheres of data were collected for $\mathrm{Cu}\left[\mathrm{Se}_{3}^{+} \mathrm{Cor}\right]$ and $\mathrm{Cu}\left[\mathrm{Br}_{8} \mathrm{He}_{3}^{-} \mathrm{Cor}\right]$ to ensure that the absolute configuration could be reliably determined from anomalous scattering. The structures were solved by intrinsic phasing $(\text { SHELXT) })^{42}$ and refined by full-matrix least squares on $F^{2}$ (SHELXL-2014). ${ }^{43}$ All nonhydrogen atoms were refined anisotropically. Hydrogen atoms were geometrically calculated and refined as riding atoms. Some disorder of the pendant groups was observed for $\mathrm{Cu}\left[\mathrm{He}_{6}^{+} \mathrm{Cor}\right]$ and $\mathrm{Cu}\left[\mathrm{Br}_{8} 5,15-\mathrm{IE}_{2}^{ \pm}-10-\mathrm{YC}_{0}^{\mp} \mathrm{Cor}\right]$, and these have been modelled over multiple sites. SQUEEZE analysis was used to determine the solvent content of the voids in $\mathrm{Cu}\left[\mathrm{Br}_{8} 5,15-\mathscr{H}_{6}^{ \pm}{ }_{2}-10-\mathrm{IC}_{6}^{\mp} \mathrm{Cor}\right]$, as the solvent of crystallization was too disordered for modeling attempts. Additional crystallographic information has been summarized in Tables 1 to 4 and full details can be found in the crystallographic information files provided as Supporting Information.

Acknowledgements. The above work was supported by grants 231086 and 262229 of the Research Council of Norway. This research also used resources of the Advanced Light Source, which is a DOE Office of Science User Facility under contract no. DE-AC02-05CH11231. We thank Dr. Soizic Chevance for stimulating discussions and recording the CD spectra. 


\section{References}

${ }^{1}$ Moscowitz, A. Theoretical Aspects of Optical Activity. Part 1: Small Molecules. Adv. Chem. Phys. 1962, 4, 67-112.

${ }^{2}$ Kwit, M.; Skowronek, P.; Gawronski, J.; Frelek, J.; Woznica, M.; Butkiewicz, A. In Comprehensive Chiroptical Spectroscopy, Vol. 2, Applications in Stereochemical Analysis of Synthetic Compounds, Natural Products, and Biomolecules. Berova, N.; Polavarapu, P. L.;

Nakanishi, K.; Woody, R. W. (eds.), Wiley, New York, 2012, Ch. 2, pp. 39-72.

${ }^{3}$ Mislow, K.; Siegel, J. Stereoisomerism and Local Chirality. J. Am. Chem. Soc. 1984, 106, 3319-3328.

${ }^{4}$ She, Y.; Chen, C.-F. Helicenes: Synthesis and Applications. Chem. Rev. 2012, 112, 1463-1535.

${ }^{5}$ Thilgen, C.; Gosse, I.; Diederich, F. Chirality in Fullerene Chemistry. Top. Stereochem. 2003, 23, 1-124.

${ }^{6}$. Ghosh, A. Electronic Structure of Corrole Derivatives: Insights from Molecular Structures, Spectroscopy, Electrochemistry, and Quantum Chemical Calculations. Chem. Rev. 2017, 117, 3798-3881.

${ }^{7}$. Gross, Z.; Galili, N. N-Substituted Corroles: A Novel Class of Chiral Ligands. Angew. Chem. Int. Ed. 1999, 38, 2366-2369.

${ }^{8}$. Wasbotten, I. H.; Wondimagegn, T.; Ghosh, A. Electronic Absorption, Resonance Raman, and Electrochemical Studies of Planar and Saddled Copper(III) Meso-Triarylcorroles. Highly Substituent-Sensitive Soret Bands as a Distinctive Feature of High-Valent Transition Metal Corroles. J. Am. Chem. Soc. 2002, 124, 8104-8116.

${ }^{9}$ Ou, Z.; Shao, J.; Zhao, H.; Ohkubo, K.; Wasbotten, I. H.; Fukuzumi, S.; Ghosh, A.; Kadish, K. M. Spectroelectrochemical and ESR Studies of Highly Substituted Copper Corroles. $J$. Porphyrins Phthalocyanines 2004, 8, 1236-1247.

${ }^{10}$ Bröring, M.; Bregier, F.; Tejero E. C.; Hell, C.; Holthausen M. C. Revisiting the Electronic Ground State of Copper Corroles. Angew. Chem., Int. Ed. 2007, 46, 445-448.

${ }^{11}$ Thomas, K. E.; Alemayehu, A. B.; Conradie, J.; Beavers, C.; Ghosh, A. Synthesis and Molecular Structure of Gold Triarylcorroles. Inorg. Chem. 2011, 50, 12844-12851.

${ }^{12}$ Berg, S.; Thomas, K. E.; Beavers, C. M.; Ghosh, A. Undecaphenylcorroles. Inorg. Chem. 2012, 51, 9911-9916. 
13 Thomas, K. E.; Beavers, C. M.; Ghosh, A. Molecular Structure of a Gold $\beta$ -

Octakis(trifluoromethyl)-meso-triarylcorrole: An 85 Difference in Saddling Dihedral Relative to Copper. Mol. Phys. 2012, 110, 2439-2444.

${ }^{14}$ Alemayehu, A. B.; Hansen, L. K.; Ghosh, A. Nonplanar, Noninnocent, and Chiral: A Strongly Saddled Metallocorrole. Inorg. Chem. 2010, 49, 7608-7610.

15 Thomas, K. E.; Vazquez-Lima, H.; Fang, Y.; Song, Y.; Gagnon, K. J.; Beavers, C. M.; Kadish, K. M.; Ghosh, A. Ligand Noninnocence in Coinage Metal Corroles: A Silver Knife-Edge. Chem. - Eur. J. 2015, 21, 16839-16847.

16 Thomas, K. E.; Wasbotten, I. H.; Ghosh, A. Copper $\beta$-Octakis(Trifluoromethyl)Corroles: New Paradigms for Ligand Substituent Effects in Transition Metal Complexes. Inorg. Chem. 2008, 47, $10469-10478$.

17 Thomas, K. E.; Conradie, J.; Hansen, L. K.; Ghosh, A. A Metallocorrole with Orthogonal Pyrrole Rings. Eur. J. Inorg. Chem. 2011, 1865-1870.

${ }^{18}$ Schies, C.; Alemayehu, A. B.; Vazquez-Lima, H.; Thomas, K. E.; Bruhn, T.; Bringmann, G.;

Ghosh, A. Metallocorroles as Inherently Chiral Chromophores: Resolution and Electronic Circular Dichroism Spectroscopy of a Tungsten Biscorrole. Chem. Commun. 2017, 53, 61216124.

${ }^{19}$ Alemayehu, A. B.; Vazquez-Lima, H.; McCormick, L. J.; Ghosh, A. Relativistic Effects in Metallocorroles: Comparison of Molybdenum and Tungsten Biscorroles. Chem. Eur. J. 2016, 22, 6914-6920.

${ }^{20}$ Alemayehu, A. B.; Vazquez-Lima, H.; Gagnon, K. J.; Ghosh, A. Tungsten Biscorroles: New Chiral Sandwich Compounds. Chem. Eur. J. 2016, 22, 6914-6920.

${ }^{21}$ Halterman, R. L.; Jan, S. T. Catalytic Asymmetric Epoxidation of Unfunctionalized Alkenes Using the First $D_{4}$-Symmetric Metallotetraphenylporphyrin. J. Org. Chem. 1991, 56, 5253-5254. ${ }^{22}$ Halterman, R. L., Mei, X. Synthesis of $D_{2}$-Symmetric 5,10,15,20-Tetraarylporphyrins from $C_{2}$-Symmetric Benzaldehydes and Achiral Aryldipyrromethanes. Tetrahedron Letters. 1996, 37, 6291-6294.

${ }^{23}$ Koszarna, B.; Gryko, D. T. Efficient Synthesis of meso-Substituted Corroles in a $\mathrm{H}_{2} \mathrm{O}-\mathrm{MeOH}$ Mixture. J. Org. Chem. 2006, 71, 3707-3717. 
${ }^{24}$ Halterman, R. L.; Jan, S-T, Nimmons, H. L.; Standlee, D. J.; Khan, M. A. Synthesis and Catalytic Reactivity of $D_{4}$-Symmetric Dinorbornabenzene-derived Metallotetraarylporphyrins. Tetrahedron 1997, 53, 11257-11276.

${ }^{25}$ Wang, J-C.; Zhang, Y.; Xu, Z-J.; Lo, V. K-Y.; Che, C-M. Enantioselective Intramolecular Carbene C-H Insertion Catalyzed by a Chiral Iridium(III) Complex of $D_{4}$-Symmetric Porphyrin Ligand. ACS Catal. 2013, 3, 1144-1148.

${ }^{26}$ Thu, H-Y.; Tong, G. S-M.; Huang, J-S.; Chan, S. L-F.; Deng, Q-H.; Che, C-M. Highly Selective Metal Catalysts for Intermolecular Carbenoid Insertion into Primary $\mathrm{C}-\mathrm{H}$ Bonds and Enantioselective C-C Bond Formation. Angew. Chem. Int. Ed. 2008, 47, 9747-9751.

${ }^{27}$ Nicolas, I.; Chevance, S.; Le Maux, P.; Simonneaux, G. Chiral Recognition of Amines and Amino Acid Derivatives by Optically Active Ruthenium Halterman Porphyrins in Organic Solvents and Water. Tetrahedron: Asymmetry 2010, 21, 1788-1792.

${ }^{28}$ Halterman, R. L.; Jan, S-T.; Abdulwali, A.H.; Standlee, D. J. Synthesis and Catalytic Reactivity of Sterically and Electronically Modified $D_{4}$-Symmetric Metallotetraarylporphyrins. Tetrahedron 1997, 53, 11277-11296.

${ }^{29}$ Amiri, N.; Le Maux, P.; Srour, H.; Nasri, H.; Simonneaux, G. Nitration of Halterman Porphyrin: a New route for Fine-tuning Chiral Iron and Manganese Porphyrins with Application in Epoxidation and Hydroxylation reactions using Hydrogen Peroxide as Oxidant. Tetrahedron 2014, 70, 8836-8842.

${ }^{30}$ Srour, H.; Le Maux, P.; Simmoneax, G. Enantioselective Manganese-Porphyrin-Catalyzed Epoxidation and C-H hydroxylation with Hydrogen Peroxide in Water/Methanol Solutions. Inorg. Chem. 2012, 51, 5850-5856.

31 Jones, J. E.; Ruppel, J. V.; Gao, G.-Y.; Moore, T. M.; Zhang, X. P. Cobalt-Catalyzed Asymmetric Olefin Aziridination with Diphenylphosphoryl Azide. J. Org. Chem. 2008, 73, $7260-7265$.

32 Subbarayan, V.; Ruppel, J. V.; Zhu, S.; Perman, J. A.; Zhang, X. P. Highly Asymmetric Cobalt-Catalyzed Aziridination of Alkenes with Trichloroethoxysulfonyl Azide (TcesN $\left.\mathrm{N}_{3}\right)$. Chem. Commun. 2009, 4266-4268

33 Jiang, H.; Lang, K.; Lu, H.; Wojtas, L.; Zhang, X. P. Asymmetric Radical Bicyclization of Allyl Azidoformates via Cobalt(II)-Based Metalloradical Catalysis. J. Am. Chem. Soc. 2017, 139, 9164-9167. 
${ }^{34}$ Lai, T-S.; Chan, F-Y.; So, P-K.; Ma, D-L.; Wong, K-Y.; Che, C-M. Alkene Cyclopropanation Catalyzed by Halterman Iron Porphyrin: Participation of Organic Bases as Axial Ligands. Dalton Trans. 2006, 4845-4851.

${ }^{35}$ Che, C. M.; Huang, J. S.; Lee, F. W.; Li, Y.; Lai, T. S.; Kwong, H. L.; Teng, P. F.; Lee, W. S.; Lo, W. C.; Peng, S. M.; Zhou, Z. Y. Asymmetric Inter- and Intramolecular Cyclopropanation of Alkenes Catalyzed by Chiral Ruthenium Porphyrins. Synthesis and Crystal Structure of a Chiral Metalloporphyrin Carbene Complex. J. Am. Chem. Soc. 2001, 123, 4119-4129.

${ }^{36}$ Nicolas, I.; Le Maux, P.; Simonneaux, G. Synthesis of Chiral Water-soluble Metalloporphyrins (Fe, Ru,): New catalysts for Asymmetric Carbene Transfer in Water. Tetrahedron Lett. 2008, 49, 5793-5795.

37 . Nicolas, I.; Roisnel, T.; Le Maux, P.; Simonneaux, G. Asymmetric Intermolecular Cyclopropanation of Alkenes by Diazoketones Catalyzed by Halterman Iron Porphyrins. Tetrahedron Lett. 2009, 50, 5149-5151.

${ }^{38}$ Chen. Y.; Ruppel, J. V.; Zhang, X. P. Cobalt-Catalyzed Asymmetric Cyclopropanation of Electron-Deficient Olefins. J. Am. Chem. Soc. 2007, 129, 12074-12075

39 . Rose, E.; Andrioletti, B.; Zriga, S.; Quelquejeu-Ethève, M. Enantioselective epoxidation of olefins with chiral metalloporphyrin catalysts. Chem. Soc. Rev. 2005, 34, 573-583.

${ }^{40}$ Simonneaux, G.; Le Maux, P.; Chevance, S.; Srour, H. Recent Advances in Catalysis by Water-Soluble Metalloporphyrins. In Handbook of Porphyrin Science. Kadish, K. M.; Smith, K. M.; Guilard, R. (eds.). 2012, Vol. 21, pp. 377-410.

${ }^{41}$ Simonneaux, G.; Srour, H.; Le Maux, P.; Chevance, S.; Carrie, D. Metalloporphyrin Symmetry in Chiral Recognition and Enantioselective Catalysis. Symmetry 2014, 6, 210-221. 42 Sheldrick, G. M. SHELXT - Integrated Space-Group and Crystal-Structure Determination. Acta Cryst. 2015, A71, 3-8.

${ }^{43}$ Sheldrick, G. M. Crystal Structure Refinement with SHELXL. Acta Cryst. 2015, C71, 3-8. 